\title{
Tracheal Stenosis
}

\section{Colbert Perez MD, Ralph Paone MD, and Raed Alalawi MD}

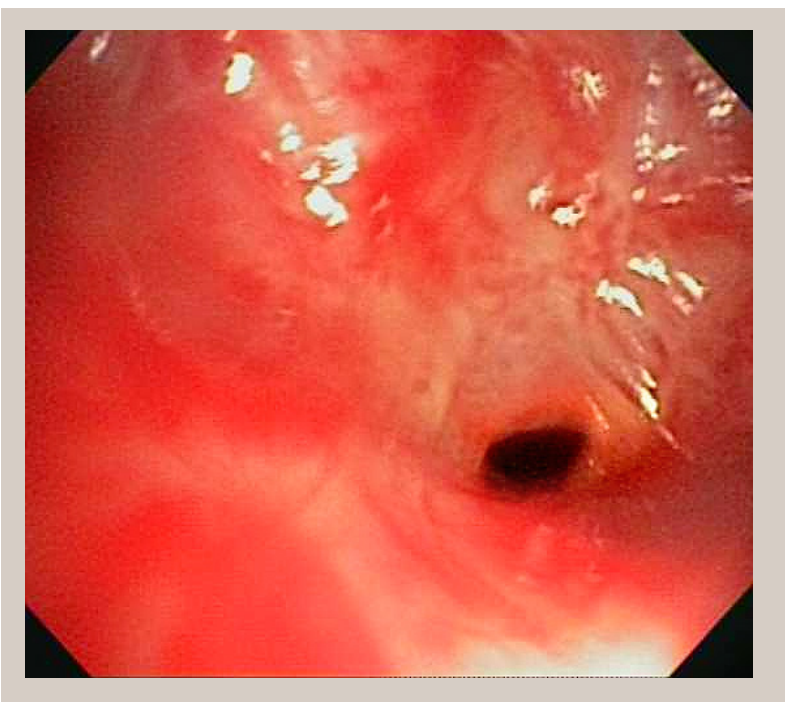

Figure 1 Initial bronchoscopy demonstrating tracheal stenosis with an airway size of 2-4 $\mathrm{mm}$.

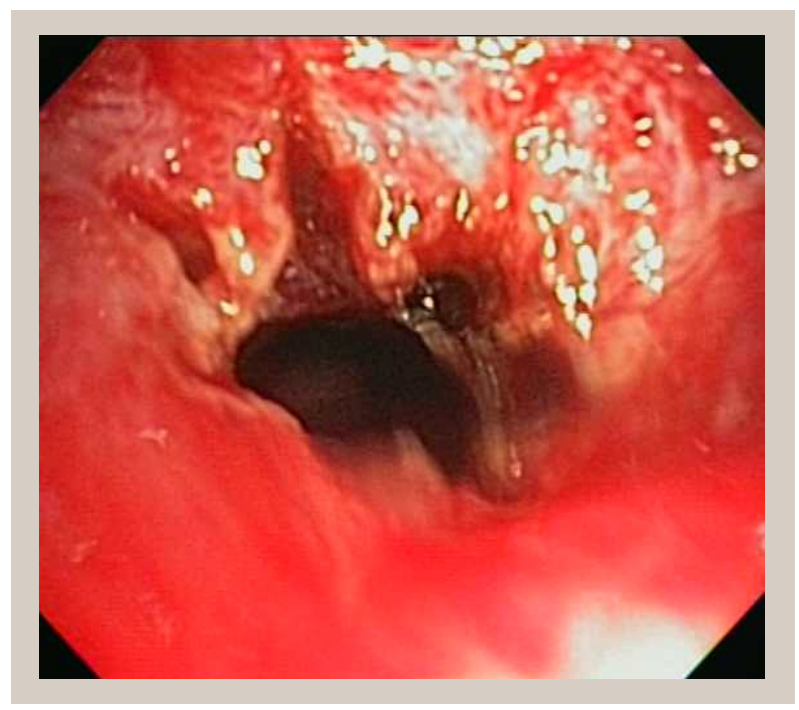

Figure 2 After balloon dilation with $15 \mathrm{~mm}$ balloon and an approximate airway size of $10 \mathrm{~mm}$.

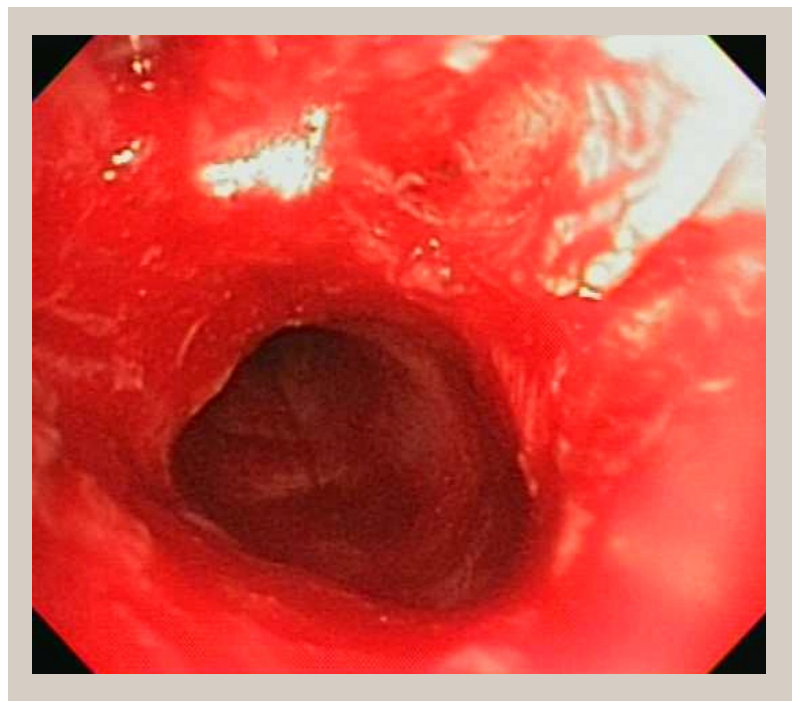

Figure 3 After Endoscopic electrosurgery and balloon dilation

A 43-year-old woman with a history of asthma presented with five months of worsening dyspnea unresponsive to her current asthma therapy. Her

Corresponding author: Colbert Perez

Contact Information: colbert.perez@

ttuhsc.edu

DOI: 10.12746/swrccc 2013.0102.019 symptoms began one month after an asthma exacerbation that was complicated by pneumonia and required intubation. Upon arrival her oxygen saturations were $79 \%$, and she had significant stridor and respiratory distress. A non-rebreather mask was required to maintain oxygen saturations above $90 \%$. After being placed on a 70/30 heliox mixture, her work of breathing greatly improved. Bronchoscopy and endoscopic treatment relieved her dyspnea (Figures1-3). 
Adult tracheal stenosis secondary to intubation has a reported incidence of $0.6-21 \%$ and is presumed to be related to cuff injury in $31 \%$ of cases (1). It may take 30 days to develop after extubation, and the diagnosis is best made by bronchoscopy (2). However, helical CT with reconstruction has 93\% sensitivity and $100 \%$ specificity (3). Heliox mixtures can reduce the work of breathing in the acute setting and helped in this case. The low density of heliox reduces turbulent airflow which decreases airway resistance, pleural pressure swings, and dynamic hyperinflation (4). The best treatment for adult tracheal stenosis is endobronchial laser resection, but complex lesions may require surgical resection and/or stents.

Received: $3 / 19 / 13$

Revised: $3 / 22 / 13$

Accepted: $3 / 25 / 13$

Published online: $4 / 16 / 13$

Reviewers: Kenneth Nugent MD

Conflict of Interest Disclosures: None

\section{References}

1. Grillo HC. Management of nonneoplastic diseases of the trachea. In: Shields TW, LoCicero J III, Ponn RB, editors. General thoracic surgery. Vol 1. 5th ed. Philadelphia: Lippincott Williams \& Wilkins; 2000. p. 885-97.

2. Sarper A, Ayten A, Eser I, et al. Tracheal stenosis after tracheostomy or intubation: review with special regard to cause and management. Tex Heart Inst J 2005; 32:154-158.

3. Herrera P, Caldarone C, Forte V, et al. The current state of congenital tracheal stenosis. Pediatr Surg Int 2007; 23:103344.

4. Feller-Koppman D, Odonnel C. Physiology and clinical use of heliox. UptoDate. Waltham, MA, 2013. 